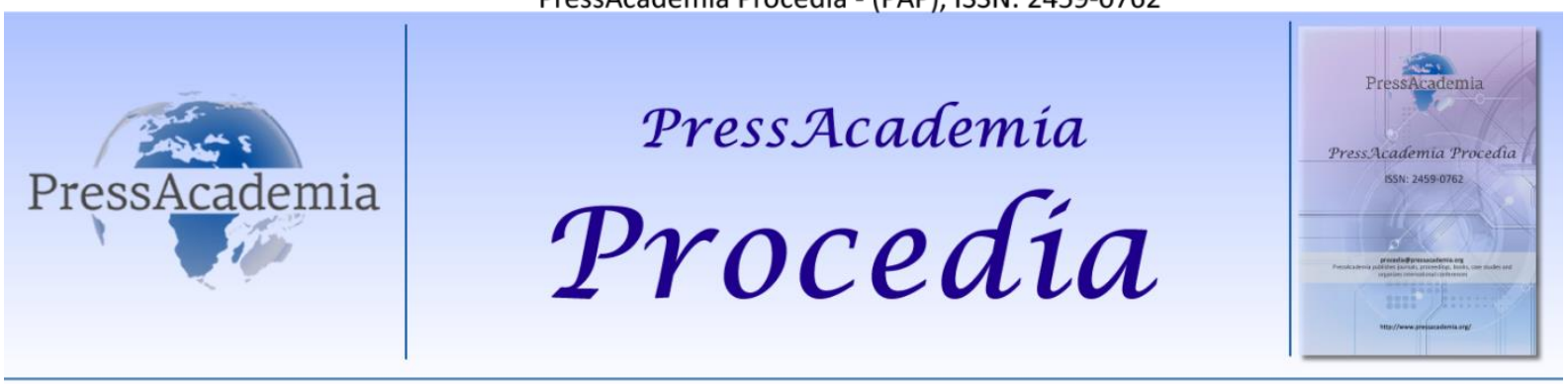

Global Business Research Congress (GBRC), May 24-25, 2017, Istanbul, Turkey.

\title{
COMPARISON OF AIRLINE DESTINATIONS IN TERMS OF ONLINE CONSUMER BEHAVIORS USING MULTI DIMENSIONAL SCALE ANALYSIS
}

\author{
DOI: 10.17261/Pressacademia.2017.671 \\ PAP-GBRC-V.3-2017(98)-p.891-899
}

Bahri Baran Kocak ${ }^{1}$, Ozlem Atalik ${ }^{2}$, Cem Burak Kocak ${ }^{3}$

${ }^{1}$ Anadolu University. bbkocak@anadolu.edu.tr

${ }^{2}$ Anadolu University. oatalik@anadolu.edu.tr

${ }^{3}$ Anadolu University. c_b_k@anadolu.edu.tr

\section{To cite this document}

Kocak, B.B., O. Atalik and C.B.Koc, (2017). Comparison of airline destinations in terms of online consumer behaviours using multi dimentional scale analysis. PressAcademia Procedia (PAP), V.3, p.883-899.

Permemant link to this document: $h$ ttp://doi.org/10.17261/Pressacademia.2017.670

Copyright: Published by PressAcademia and limited licenced re-use rights only.

\begin{abstract}
With digital media becoming an important position in mass communication, information is shared and spread to those who use this media. Twitter in digital media is one of the most popular social media platforms that has come up with the combination of social network sites and blogs, with millions of members and the ability to share and spread information quickly. Sharing of information via electronic word of mouth (e-WOM) is one of the important issues that attract the attention of marketers. In this respect, this behavior of social media users is very important in sharing information by sharing, retweeting or liking of any posts on Twitter, as it is displayed by other users on their friends list. This study aims to find out the location of each destination according to the share, retweet, likes and reasons for reccommendation of users by looking at the destinations that are shared by Turkish Airlines (THY) on Twitter in 2016. The study will reveal how our country is in relation to other destinations and the tendency of Turks to other destinations to be seen in concrete terms. By using multidimensional scaling analysis, the locations of Turkey and other destinations can be displayed and evaluated in two dimensional space.
\end{abstract}

Keywords: Social media, E-Wom, Twitter, share, retweet, favorite, online consumer behavior

JEL Codes: M30, M31, L82

\section{ÇEVRIMIÇi TÜKETICI DAVRANIŞI BAKIMINDAN ÇOK BOYUTLU ÖLÇEKLEME ANALIZi ILE HAVAYOLU DESTINASYONLARININ KARŞILAŞTIRILMASI}

\section{ÖZET}

Dijital medyanın kitle iletişiminde önemli bir konuma gelmesiyle birlikte bilgi, bu medyayı kullanan kişilerce paylaşılmış ve yayılmıştır. Dijital medyada yer alan Twitter ise sosyal ağ siteleri ile blogların bir araya gelmesiyle ortaya çıkmış, milyonlarca üyesi bulunan ve bilginin hızla paylaşılıp yayılmasını sağlayan popüler sosyal medya platformlarından biri haline gelmiştir. Bilginin elektronik ortamlarda ağızdan ağıza paylaşımı, pazarlamacıların ilgisini çeken önemli konular arasındadır. Bu doğrultuda Twitter' da yer alan herhangi bir gönderinin paylaşılması, retweet edilmesi ya da beğenilmesi, kişi arkadaş listesinde yer alan diğer kullanıcılar tarafından da görüntülendiğinden bilgi paylaşımı hususunda sosyal medya kullanııılarının bu davranışı oldukça önem arz etmektedir. Twitter' da Türk Hava Yolları (THY) tarafından 2016 yııında paylaşılan destinasyonlara yönelik gönderilere bakılarak kullanıııların paylaşım, retweet, beğeni ve tavsiye sebebine göre her bir destinasyonun konumunun elde edilmesinin amaçlandığı bu çalışmada, ülkemizin diğer destinasyonlara nazaran nasıl bir konumda olduğu ortaya çıkarılabilecek ve bütün ülke destinasyonlarına yönelik Türklerin eğilimi somut olarak görülebilecektir. Araştırmada çok boyutlu ölçekleme analizi kullanılarak Türkiye ve diğer destinasyonların konumları iki boyutlu uzayda görüntülenebilecek ve değerlendirilebilecektir.

Anahtar Kelimeler: sosyal medya, elektronik ağızdan ağıza pazarlama, Twitter, paylaşım, retweet, beğeni, çevrimiçi tüketici davranış JEL Kodları: M30, M31, L82 


\section{GiRiş}

Çevrimiçi söylemin bir yansıması olan sosyal medya, kişilerin yarattı̆̆ı içeriği, birbirlerini etiketleyerek bir ağ içerisinde paylaşmasına olanak tanıyan bir platformdur (Asur ve Huberman, 2010). Başka bir deyişle sosyal medya; "katılımcılarının online ortamlarda kendilerini ifade etme, iletişime geçme, gruplara katılma ve bu ortamlara fikir, yorum ve yayınlarıyla katkıda bulunma imkanı sağlayan sosyal içerikli web siteleridir" (Köksal ve Özdemir, 2013).

1979 yılında Duke Üniversitsi' nden Tom Truscott ve Jim Ellis' in dünya çapında bir buluşma noktası olarak tasarladığı internet (Kaplan ve Haenlein, 2010), 2000' li yıllarda sosyal medyanın ortaya çıkışıla hemen herkesi ilgilendiren bir seviyeye ulaşmıştır (Vural ve Bat, 2010). Bugün dünyada 2.789 milyar sosyal medya kullanıcısı bulunmakta ve bu sayı her geçen yıl artmaktadır. Örneğin 2017 yılında bir önceki yıla göre sosyal medya kullanıcı sayısı 482 milyon kişi artış göstermiştir. Sosyal medyanın bu yoğun kullanıcı istatistiklerine bakıldığında ise özellikle tüketicilerin ürün, marka, kişi ya da olaylar hakkında üretilmiş çevrimiçi içerikle birbirlerini bilgilendirdikleri görülmektedir (Mangold ve Faulds, 2009).

Geleneksel medya kanallarından farklı olarak sosyal medya kanalları, tüketicilerin bu platformlardaki etkin rolüyle, işletmeler açısından pazarlama faaliyetlerine yeni bir soluk getirmektedir. Özellikle tutundurma karması elemanları olan kişisel satış, reklam, tutundurma, halkla ilişkiler ve doğrudan pazarlama kavramları, sosyal medyanın kullanımıyla birlikte işletmelere farklı stratejiler yaratma hususunda çeşitli avantajlar sağlamaktadır. Satış açısından bakıldığında kişi veya grupların ürün veya hizmet hakkında sosyal medyadan edindiği bilgiyle daha kolay ikna olmaları; reklam açısından bakıldığında ürüne karşı istek ve ihtiyacın tercih oluşturacak biçimde hızla yayılıp kullanıcıların birçoğuna ulaşması; satış tutundurma açısından bakıldığında paylaşım ve beğeniye dair kampanyaların yapılması; halkla ilişkiler açısından bakıldığında yazılan mesajların cevaplanması, sorunların çözülmesi ya da çözecek birimleri harekete geçirmesi ve son olarak doğrudan pazarlama açısından ise sosyal medya aracılığı ile yeni satış kanallarının oluşturulması çevrimiçi sosyal platformların pazarlamaya kattığı gücü ortaya koymaktadır (Köksal ve Özdemir, 2013). Bu doğrultuda birçok işletme hemen her sosyal medya kanalında faaliyet göstermekte ve ürün ya da hizmetlerine yönelik bilgilendirmeleri kullanıcısı oldukları sosyal medya platformlarından yapmaktadırlar.

Bu çalışmanın amacı, sosyal medya platformlarından biri olan Twitter' da 2016 yılı içerisinde Türk Hava Yolları (THY) tarafından tavsiye edilen havayolu destinasyonlarının ülke bazında konumlarının Çok Boyutlu Ölçekleme (ÇBÖ) analizi ile ortaya çıkarılması ve Twitter kullanıcılarının tavsiye nedenlerine, beğeni ve paylaşım sayılarına bağı olarak eğilimlerinin görsel hale getirilmesidir. Çalışmanın ilerleyen kısımlarında bir sosyal medya platformu olan Twitter ve Türkiye' deki kullanımının yanında paylaşım davranışının altında yatan nedenlere yer verilecek, ardından kullanılan veri seti ve yöntem ele alınacak, son olarak ise bulgular verilerek elde edilen sonuçlar tartışılacaktır.

\section{TWITTER VE TÜRKIYE' DEKI KULLANIMI}

Sosyal Medya, "Web 2.0'ın ideolojik ve teknolojik temellerini oluşturan ve kullanıcı tarafından üretilen içeriğin oluşturulmasına ve değiştirilmesine olanak tanıyan İnternet tabanlı bir grup uygulama" olarak tanımlanmaktadır (Kaplan ve Haenlein, 2010). Sosyal medya kanalları arasında sosyal paylaşım siteleri, fotoğraf paylaşım siteleri, video paylaşım siteleri, iş ağı siteleri, mikro blog siteleri ve diğerleri yer almaktadır. Facebook, Flickr, Youtube, Linkedın ve Twitter en popüler sosyal medya platformları arasındadır. Sosyal medya siteleri ucuzdur ve kullanımı tamamen ücretsizdir (Whiting ve Williams, 2013).

Bugün dünyada 2.789 milyar sosyal medya kullanıcısı bulunmakta ve bu sayı her geçen yıl artmaktadır. Örneğin 2017 yılında bir önceki yıla göre sosyal medya kullanıcı sayısı 482 milyon kişi artış göstermiştir. Ülke bazında sosyal medyanın topluma nüfuzuna bakıldığında ise Türkiye, \%60 nüfuz oranıyla üst sıralarda yer almaktadır. Aktif kullanıcı sayılarından yola çıkılarak sosyal medya platformlarının küresel seviyede sıralamasına bakıldığında Facebook, Whatsapp ve Youtube kanallarının bir milyarın üzerinde kullanıcı sayılarıyla ilk sıralarda olduğu görülmektedir. Bu çalışmaya konu olan Twitter, 317 milyon aktif kullanıcısı ile Instagram' ın arkasından 10. sırada yer almaktadır. Türkiye' de ise 2017 yılı verilerine göre Twitter; Youtube, Facebook ve Instagram' ın arkasından \%44 aktif kullanıcı oranı ile 4. sırada gelmektedir. ${ }^{1}$

İletişimin farklı bir pratiği olarak Twitter, bireylerin, grupların ya da büyük kitlelerin aralarında 140 karakterlik cümlelerle sohbet ettiği ve bu sohbetin muhattaplarından çok daha fazlasına ulaştığı bir mikroblog hizmetidir (Boyd vd., 2010). Dolayısıyla Twitter' ın her kesimden kişi ve kuruluş tarafından kullanıldığını söylemek yerinde bir yaklaşım olacaktır. Bu bağlamda diğer herkes gibi tüketiciler de sosyal medyada yer alan içeriği tüketmekte, tartışmalara katılmakta, bilgi paylaşımında bulunmakta ve diğer tüketicilerin eylemlerine katkıda bulunmaktadırlar. Bu davranış biçimleri medya ve pazarlama altyapısını hızla değiştirmekte ve işletmelerin pazarlama alanına müdahale etmektedir (Berthon vd., 2008; Heinonen, 2011). Twitter, bilgilenme ve paylaşım temelli bir sosyal medya platformu olduğundan ötürü kullanıcıların bu

\footnotetext{
${ }^{1}$ https://wearesocial.com/blog/2017/01/digital-in-2017-global-overview (Erişim Tarihi: 09.05.17)
} 
davranışlarının altında yatan nedenlerin bilinmesi de sosyal medyayı aktif kullanan işletmeler açısından oldukça önem arz etmektedir. Bu doğrultuda Retweet ya da paylaşma davranışının altında yatan diğer muhtemel sebepler (Boyd vd., 2010);

- $\quad$ Gönderinin daha güçlü hale gelerek yeni izleyicilere ulaşmasını sağlamak,

- Belirli bir kitleyi eğlendirmek ya da bilgilendirmek veya bir görseli sergilemek,

- $\quad$ Yorum yapmak ya da bir gönderiye yeni bir içerik eklemek,

- $\quad$ Bir kullanıcısının takipçisi, dinleyicisi olduğunu belli etmek,

- $\quad$ Birilerine fikirsel veya ideolojik anlamda topluluk olarak katıldığını belli etmek,

- Başkalarının düşüncelerini onaylamak,

- $\quad$ Arkadaşlık, sadakat göstermek ya da ilgi çekmek,

- Daha az popüler insanlara ya da az görünür içeriklere farkındalık getirmek,

- $\quad$ Karşılıklı takipçi kazanmak ve

- Gelecekte tekrar ulaşmak için tweeti saklamak şeklinde sıralanabilir.

\section{METODOLOJI}

Çok Boyutlu Ölçekleme (ÇBÖ) nesne çiftleri arasındaki benzerlik ya da benzemezliklerin çok boyutlu uzayda az boyuta indirgenerek noktalar arası uzaklıklarla ölçümünü sağlayarak görselleştiren bir yöntemdir (Borg ve Groenen, 2005: 3). Bu yöntem; kişisel tercihler, tutumlar, eğilimler, inançlar ve beklentiler gibi davranış özelliği gösteren verilerin analizlerinde kullanılabilmektedir (Oğuzlar, 2005b: 35; Tüzüntürk, 2009). ÇBÖ’ nün uygulanması için veri ve değişken sayısının elle hesaplanabilmenin ötesinde yüksek olması gerekmektedir. Dolayısıyla bu analiz tekniği, karmaşık problemleri daha anlaşıır kılmakla birlikte, birimlerarası sınıflandırmaya ve değişkenlerarası bağımlıık yapısını ortadan kaldırarak verilerin daha az boyutta incelenebilmesini sağlamaktadır (Bülbül ve Köse, 2010).

ÇBÖ’ de $\mathrm{n}$ adet nokta ile geometric olarak gösterilen $\mathrm{n}$ nesnenin aralarındaki benzemezlik ve uzaklıkların ilişkisi hesaplanmakta ve uyum optimizasyonu yapılmaktadır. İşlem altı adımdan oluşmaktadır.

Adım 1: Problem tanımlanarak veri ve değişkenler oluşturulur. Veri matrisi $\left(\mathrm{X}_{\mathrm{ij}}\right)$ hazırlanırken tüm verilerin aynı ölçekte hazırlanması gerekmektedir.

$$
x=\left[\begin{array}{ccc}
x_{11} & x_{12} & x_{13} \\
x_{21} & x_{22} & x_{23} \\
\vdots & \vdots & \vdots \\
x_{p 1} & x_{p 2} & x_{p 3}
\end{array}\right]
$$

Adım 2: T boyutlu uzayda i. ve j. noktalar arası uzaklık aşağıdaki eşitlikle ifade edilmektedir (Kruskal, 1964):

$$
d_{i j}=\sqrt{\sum_{a=1}^{t}\left(x_{i a}-x_{j a}\right)^{2}}
$$

Adım 3: Probleme uygun boyut belirlenir. Boyut belirlenirken referans olarak stress istatistiği değerlerinden faydalanılır. En küçük stresss değeri çözüm için kullanılacak boyutu belirtir. Stress değerleri ve uygunluk ölçütleri aşağıda gösterilmiştir (Kruskal, 1964):

\begin{tabular}{|l|l|}
\hline Stress & Uygunluk ölçütü \\
\hline$\geq 0,20$ & Uyumsuz \\
\hline $0,10<0,20$ & Düşük \\
\hline $0,05<0,10$ & lyi \\
\hline $0,025<0,05$ & Mükemmel \\
\hline $0,00<0,025$ & Tam \\
\hline
\end{tabular}

Adım 4: Regresyon yöntemlerinden biriyle tahmini uzaklık matrisi elde edilir.

Adım 5: Gerçek uzaklık ile tahmini uzaklık değerleri arasındaki uyum stress istatistikleri ile belirlenir. Stress istatistiği ve uyum indeksi $\left(R^{2}\right)$ hesabı aşağıdaki gibidir (Kruskal, 1964): 


$$
S=\sqrt{\frac{\sum_{i<j}\left(d_{i j}-\hat{d}_{i j}\right)}{\sum_{i<j} d_{i j}^{2}}}
$$

Şekildeki denklemden yola çıkılarak stress istatistiğinin sıfıra, RSQ $\left(R^{2}\right)$ korelasyon katsayısının ise $1^{\prime}$ e yaklaşması gerekir. RSQ, noktalar arası yakınlık değerlerindeki varyansın yüzdesidir.

Adım 6: Boyutlardaki koordinatların grafiğe dökülmesi ve yorumu (Hair vd., 1998; Kalaycı vd., 2005; Bülbül ve Köse, 2010).

\section{BULGULAR ve YORUM}

Bu çalışmada ülke bazında havayolu destinasyonları arasında Türk Hava Yolları' nın hizmet verdiği diğer ülkelere nazaran Türkiye' nin hangi konumda olduğu belirlenmeye çalışılmıştır. Ülke konumları, THY' nin sosyal medya hesabı olan Twitter' da 1 Ocak -31 Aralık 2016 tarihleri arasında takipçilerine tavsiye ettiği ülkelere yönelik kullanıcıların beğeni, paylaşım ve retweet değişkenlerine ait veriler dikkate alınarak hesaplanmıştır. Çalışmada ayrıca tweetler tavsiye nedenlerine göre ayrılmış ve ülke konumları bu nedenlere verilen beğeni sayıları dikkate alınarak tekrar belirlenmiştir. Tavsiye nedenleri çıkarılırken tweette yer alan "tarih, manzara, fiyat, keşif, eğlence, yemek, spor, alışveriş" kelimeleri esas alınmıştır.

Veriler, SPSS 24.00 paket programındaki PROXSCAL algoritmasından yararlanılarak analiz edilmiştir. PROXSCAL, çok boyutlu nesnelerin birbirlerine olan uzaklıklarının en küçük karelerini alarak öklid uzayında daha az boyut içerisinde gösterilmesini sağlayan bir algoritmadır (Busing vd., 1997). Sosyal medyada yer alan paylaşım değişkenlerinden yola çıkılarak oluşturulan ülke verileri PROXSCAL algoritmasınca yakınlık matrisine dönüştürülmüş ve ÇBÖ analizi sonucu ülkelerin paylaşım değerlerine bağı Tablo 1' de yer alan iki boyutlu uzaydaki koordinatları elde edilmiştir. Şekil 1' e bakıldığında paylaşım değerlerine bağıı olarak Türkiye' nin diğer ülke destinasyonlarından keskin bir biçimde ayrıştığı görülmektedir. Bu durumun yanısıra Ukrayna, Kafkaslar, Fransa, İspanya, İtalya, Portekiz ülkelerinin bir küme; diğerlerinin ise ayrı bir kümede toplandığı görülmektedir. Ülkelerin birbirlerine uzaklık ve farklılılarının dağılımını ilişkisel olarak betimleyen Shepard grafiği ise Şekil 2' de gösterilmiştir. Grafiğe göre uzaklık ve farklılıklar arasında doğrusal bir uyum bulunmaktadır. Sosyal medyadaki paylaşım ve beğeni sayılarına bağlı olarak yapılan analiz sonucunda Shepard grafiğindeki uygunluğun belirlendiği stress istatistiği Tablo 2' te yer almaktadır. Buna göre analiz sonucunun tam uyum ve güvenirlilik gösterdiği görülmektedir.

Tablo 1: Ülkelerin Iki Boyutlu Uzaydaki Koordinatları

\begin{tabular}{|l|r|r|l|r|r|}
\hline \multirow{2}{*}{ Ülkeler } & \multicolumn{2}{|c|}{ Boyutlar } & \multirow{2}{*}{ Ülkeler } & \multicolumn{2}{c|}{ Boyutlar } \\
\cline { 2 - 3 } \cline { 6 - 6 } & $\mathbf{1}$ & $\mathbf{2}$ & & $\mathbf{1}$ & $\mathbf{2}$ \\
\hline ABD & -0.007 & 0.087 & Türkiye & 4.271 & -0.722 \\
\hline Kolombiya & -0.155 & -0.075 & İspanya & 0.423 & 0.668 \\
\hline Panama & -0.117 & -0.017 & İtalya & 0.518 & 0.908 \\
\hline Brezilya & -0.206 & -0.135 & Arnavutluk & -0.211 & -0.139 \\
\hline Küba & -0.016 & 0.095 & Romanya & -0.188 & -0.117 \\
\hline Venezuela & -0.112 & -0.026 & Bosna & -0.171 & -0.176 \\
\hline Balkanlar & 0.069 & -0.148 & Rusya & -0.110 & -0.063 \\
\hline Yunanistan & -0.086 & -0.100 & Sırbistan & -0.204 & -0.133 \\
\hline Hırvatistan & -0.055 & 0.038 & Ingiltere & -0.189 & -0.118 \\
\hline Bulgaristan & -0.199 & -0.129 & Letonya & -0.201 & -0.132 \\
\hline Slovakya & -0.124 & -0.039 & Malta & -0.208 & -0.155 \\
\hline Slovenya & -0.178 & -0.174 & Çin & -0.137 & -0.057 \\
\hline Macaristan & -0.183 & -0.115 & Japonya & -0.205 & -0.136 \\
\hline Karadağ & -0.210 & -0.141 & Azerbaycan & -0.189 & -0.121 \\
\hline Danimarka & -0.155 & -0.074 & Viyetnam & -0.201 & -0.133 \\
\hline Çek & -0.171 & -0.102 & Srilanka & -0.197 & -0.128 \\
\hline Norveç & -0.213 & -0.140 & İran & -0.186 & -0.116 \\
\hline Lüksemburg & -0.147 & -0.066 & Irak & -0.159 & -0.093 \\
\hline iskocya & -0.193 & -0.128 & UAE & -0.171 & -0.097 \\
\hline İsveç & -0.151 & -0.078 & Orta_Doğu & -0.091 & 0.004 \\
\hline Almanya & -0.142 & -0.053 & Kafkaslar & 0.436 & 0.804 \\
\hline Portekiz & 0.500 & 0.931 & Tataristan & -0.143 & -0.049 \\
\hline Hollanda & -0.127 & -0.046 & Mısır & -0.163 & -0.094 \\
\hline Fransa & 0.496 & 0.744 & Seyşeller & -0.100 & -0.015 \\
\hline Ukrayna & 0.464 & 0.828 & Mauritius & -0.185 & -0.115 \\
\hline GAC & -0.200 & -0.133 & Madagaskar & -0.210 & -0.139 \\
\hline Etiyopya & -0.211 & -0.140 & & & \\
\hline & & & & & \\
\hline
\end{tabular}

Tablo 2: Ülke Bazında Uyum ve Güvenilirlik Değerleri

\begin{tabular}{|l|l|}
\hline Stress (Uyum) & 0,00206 \\
\hline $\mathrm{R}^{2 \text { (Güvenilirik) }}$ & 0,99897 \\
\hline
\end{tabular}




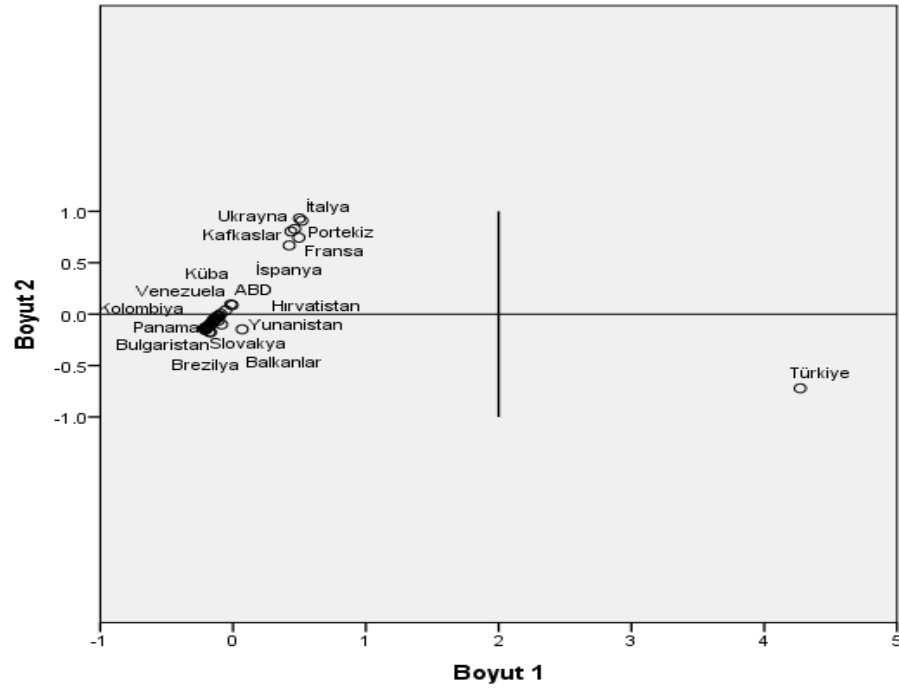

Şekil 1: Beğeni, Paylaşım ve RT oranlarına göre ülke eğilimlerinin iki boyutlu uzayda gösterimi

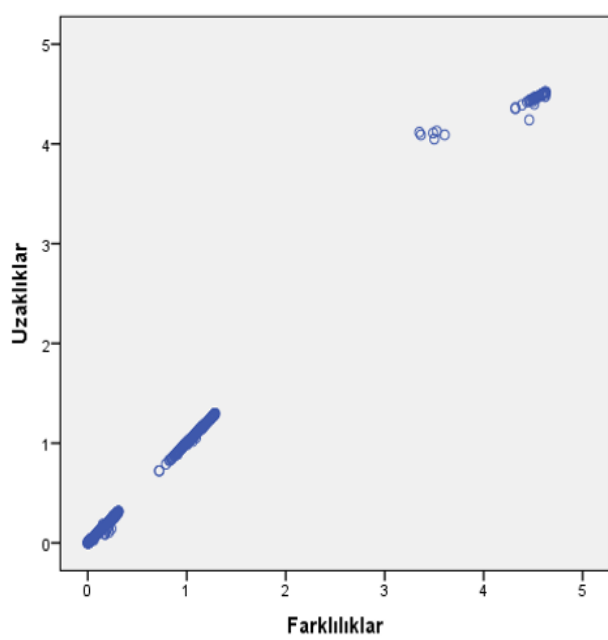

Şekil 2: Ülkeler bazında uzaklıklar ile farklılıklar arasındaki ilişkinin diyagram

Ülke destinasyonlarının ve paylaşım sayılarının paylaşım türüne bağlı olarak iki boyutlu uzaydaki koordinatları Tablo 3' te gösterilmiştir. Şekil 3' teki haritaya bakıldığında ise “beğeni sayısı”nın diğerlerinden oldukça fazla ayrıştığı görülmektedir. Buna göre paylaşılan destinasyonları izleyen Twitter kullanıcılarının beğenme davranışına daha fazla eğilim gösterdiği söylenebilir. Beğeni davranışını ardından retweet ve paylaşım davranışları takip etmektedir. Paylaşım türlerinin birbirlerine uzaklık ve farklılıklarının dağııımı ise Şekil 4' te yer almaktadır. Grafiğe göre uzaklık ve farklılıklar arasında doğrusal bir uyum bulunmaktadır. Analizin stress istatistiği ve güvenirliği Tablo 4' te verilmiştir. Analiz uyum ve güvenirliliği bu istatistiklere göre tamdır.

\section{Tablo 3: Paylaşımların íki Boyutlu Uzaydaki Gösterimi}

\begin{tabular}{|l|c|c|}
\hline \multirow{2}{*}{} & \multicolumn{2}{|c|}{ Boyutlar } \\
\cline { 2 - 3 } & $\mathbf{1}$ & $\mathbf{2}$ \\
\hline Beğeni & 0.794 & 0.022 \\
\hline Paylaşım & -0.523 & 0.091 \\
\hline Retweet & -0.271 & -0.113 \\
\hline
\end{tabular}

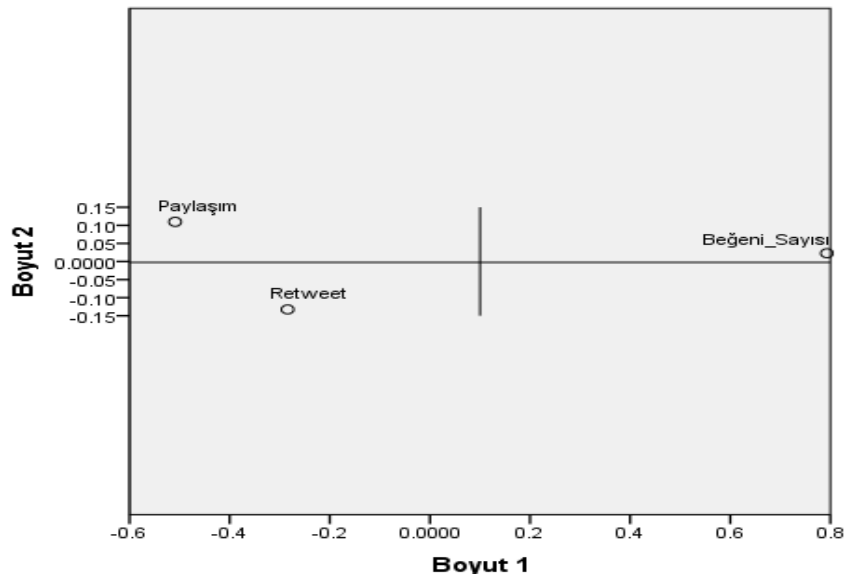

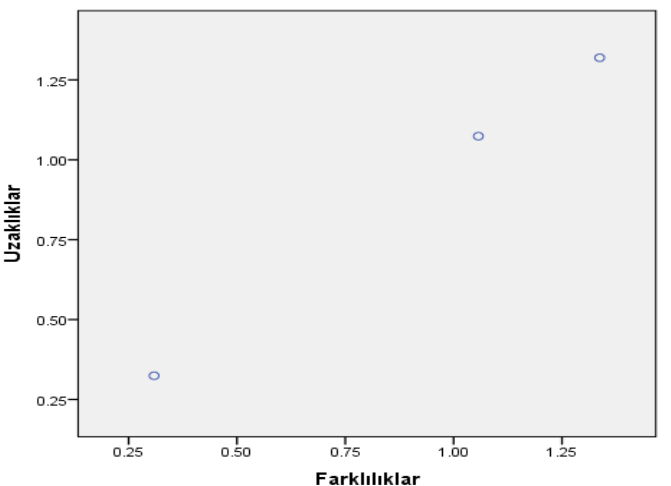

Şekil 4: Paylaşım bazında uzaklıklar ile farklılıklar arasındaki ilişkinin diyagramı

Şekil 3: Beğeni, paylaşım ve RT davranışının iki boyutlu uzayda gösterimi 
Tablo 4: Paylaşım Bazında Uyum ve Güvenilirlik Değerleri

\begin{tabular}{|c|c|}
\hline Stress (Uyum) & 0,00028 \\
\hline $\mathbf{R}^{2 \text { (Güvenilirik) }}$ & 0,99986 \\
\hline
\end{tabular}

Analiz sonucunda kullanıcıların beğenme davranışına daha fazla eğilim göstermesinden ötürü destinasyonların öne çıkarılan özellikleri beğeni sayıları referans alınarak hazırlanmıştır. Ardından THY' nin öne çıkardığı özellikler ve ülkeler birlikte ÇBÖ yöntemi ile analiz edilmiştir. Bu doğrultuda ülkelerin iki boyutlu uzaydaki koordinatları Tablo 5'te gösterilmiştir. Şekil 5' e bakıldığında Türkiye' nin Twitter' da önerilen diğer destinasyonlardan uzaklaştığı, Fransa, İtalya, İspanya, Portekiz ve Malta' nın bir küme içinde; diğer ülkelerin ise ayrı bir küme içinde gruplandığı görülmektedir. Bu durumda kullanıcıların Türkiye' ye yönelik tavsiyelere daha yüksek eğilim gösterdiği söylenebilmektedir. Destinasyonların öne çıkarılan özelliklerine göre birbirlerine uzaklık ve farklılıklarının dağılımı ise Şekil 6’ da yer almaktadır. Grafiğe göre uzaklık ve farklılıklar arasında doğrusal bir uyum bulunmaktadır. Sosyal medyadaki paylaşım ve beğeni sayılarına bağı olarak yapılan analiz sonucunda Shepard grafiğindeki uygunluğun belirlendiği stress istatistiği Tablo $6^{\prime}$ da verilmiştir. Dolayısıyla analizin uyum ve güvenirliğinin tam olduğu söylenebilmektedir.

Tablo 5: Öne Çıkarılan Özellikler Bakımından Ülkelerin Koordinatları

\begin{tabular}{|c|c|c|c|c|c|}
\hline \multirow[t]{2}{*}{ Ülkeler } & \multicolumn{2}{|c|}{ Boyutlar } & \multirow[t]{2}{*}{ Ülkeler } & \multicolumn{2}{|c|}{ Boyutlar } \\
\hline & 1 & 2 & & 1 & 2 \\
\hline ABD & -0.204 & 0.183 & İtalya & 1.747 & -0.846 \\
\hline Kolombiya & -0.284 & -0.045 & Arnavutluk & -0.049 & -0.115 \\
\hline Panama & -0.093 & 0.010 & Romanya & -0.245 & -0.080 \\
\hline Brezilya & -0.284 & -0.045 & Bosna & -0.014 & -0.115 \\
\hline Küba & -0.141 & 0.339 & Rusya & -0.284 & -0.045 \\
\hline Venezuela & -0.256 & 0.022 & Sırbistan & -0.315 & -0.041 \\
\hline Yunanistan & 1.132 & -0.559 & İngiltere & -0.305 & 0.040 \\
\hline Hırvatistan & -0.039 & 0.165 & Letonya & -0.284 & -0.045 \\
\hline Bulgaristan & -0.228 & 0.024 & Malta & 1.126 & -0.573 \\
\hline Slovakya & -0.041 & -0.017 & Çin & -0.322 & 0.148 \\
\hline Slovenya & -0.164 & 0.133 & Japonya & -0.283 & -0.015 \\
\hline Macaristan & -0.217 & -0.008 & Azerbaycan & -0.271 & -0.025 \\
\hline Karadağ & -0.277 & -0.034 & Viyetnam & -0.265 & 0.010 \\
\hline Danimarka & -0.279 & 0.006 & Srilanka & -0.266 & -0.016 \\
\hline Çek & -0.207 & -0.018 & İran & -0.239 & 0.092 \\
\hline Norveç & -0.278 & -0.035 & Irak & -0.284 & -0.045 \\
\hline Lüksemburg & -0.192 & 0.208 & UAE & -0.254 & -0.056 \\
\hline iskocya & -0.228 & -0.064 & Kafkaslar & -0.049 & -0.115 \\
\hline İsveç & -0.238 & 0.089 & Tataristan & -0.284 & -0.045 \\
\hline Almanya & 0.012 & 0.141 & Misır & -0.268 & -0.020 \\
\hline Portekiz & 1.322 & -0.474 & Seyşeller & -0.137 & 0.215 \\
\hline Hollanda & -0.301 & 0.003 & Mauritius & -0.146 & -0.046 \\
\hline Fransa & 1.182 & -0.469 & GAC & -0.151 & -0.032 \\
\hline Ukrayna & -0.022 & -0.062 & Gine & -0.282 & -0.061 \\
\hline Türkiye & 1.558 & 2.844 & Etiyopya & -0.167 & -0.072 \\
\hline İspanya & 1.226 & -0.363 & Madagaskar & -0.167 & -0.071 \\
\hline
\end{tabular}

Tablo 6: Öne Çıkarılan Özellikler Bazında Uyum ve Güvenilirlik Değerleri

\begin{tabular}{|l|l|}
\hline Stress (Uyum) & 0,0023 \\
\hline $\mathbf{R}^{2 \text { (Güvenilirik) }}$ & 0,99886 \\
\hline
\end{tabular}




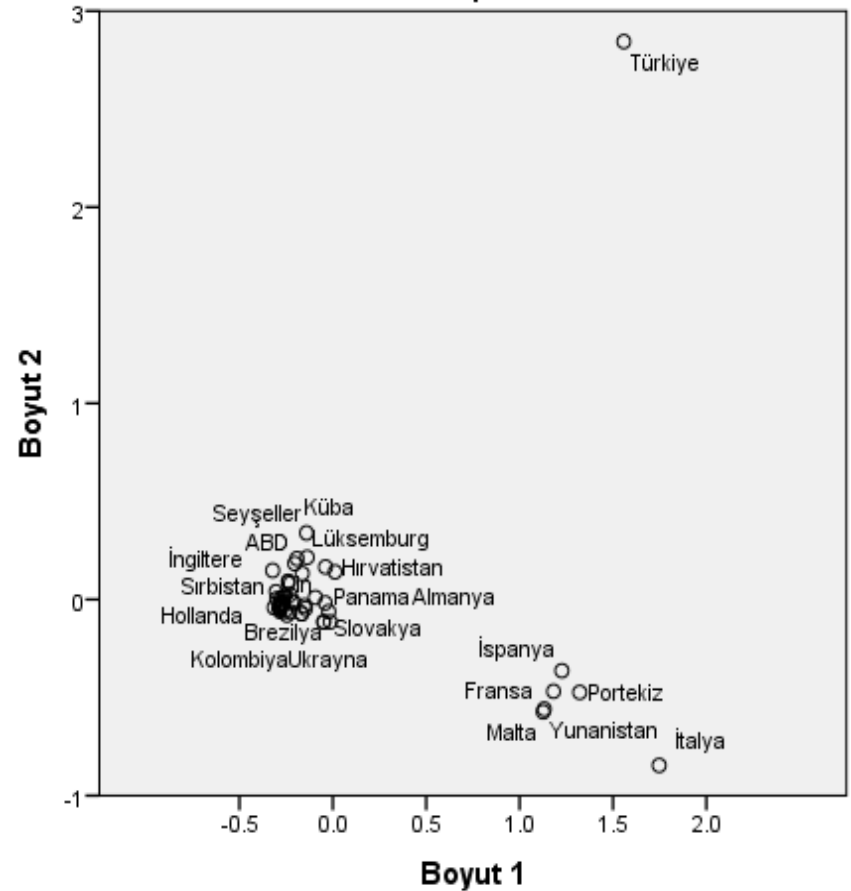

Şekil 5: Öne çıkarılan özellikler bakımından ülkelerin iki boyutlu uzayda gösterimi

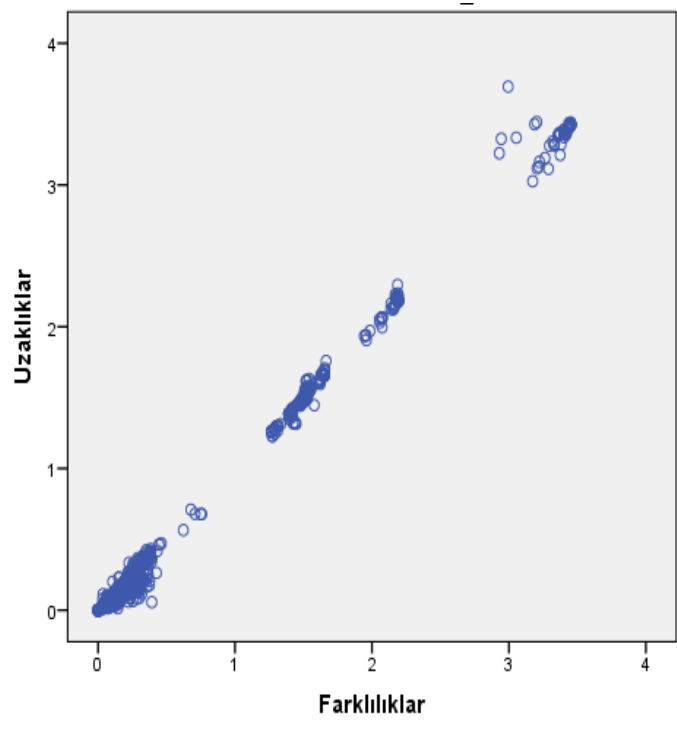

Şekil 6: Öne çıkarılan özellikler bazında ülkelerin uzaklıklar ile farklılıklar arasındaki ilişkinin diyagramı

Destinasyonlara yönelik seyahat tavsiyesi nedenlerinin iki boyutlu uzaydaki koordinatları Tablo 6’ da gösterilmiştir. Destinasyonların öne çıkarılan özelliklerinin birbirlerine uzaklık ve farklılıklarının dağılımı ise Şekil 7' de yer almaktadır. Grafiğe göre uzaklık ve farklılıklar arasında doğrusal bir uyum bulunmaktadır. Sosyal medyadaki paylaşım ve beğeni sayılarına bağlı olarak yapılan analiz sonucunda Shepard grafiğindeki uygunluğun belirlendiği stress istatistiği Tablo $7^{\prime}$ de verilmiştir.

Tablo 6: Öne Çıkarılan Özelliklerin Koordinatları

\begin{tabular}{|l|c|c|}
\hline \multirow{2}{*}{ Tarih } & \multicolumn{2}{|c|}{ Boyutlar } \\
\cline { 2 - 3 } & $\mathbf{1}$ & $\mathbf{2}$ \\
\hline Manzara & -0.172 & $\mathbf{0 . 1 1 4}$ \\
\hline Fiyat & -0.045 & 0.710 \\
\hline Keşif & 1.469 & -0.150 \\
\hline Eğlence & -0.096 & 0.361 \\
\hline Yemek & -0.200 & -0.201 \\
\hline Spor & -0.327 & -0.208 \\
\hline Alışveriş & -0.303 & -0.281 \\
\hline
\end{tabular}

Tablo 7: Öne Çıkarılan Özelliklerin Uyum ve Güvenilirlik Değerleri

\begin{tabular}{|l|l|}
\hline Stress (Uyum) & 0,0011 \\
\hline $\mathbf{R}^{2 \text { (Güvenilirlik) }}$ & 0,99945 \\
\hline
\end{tabular}




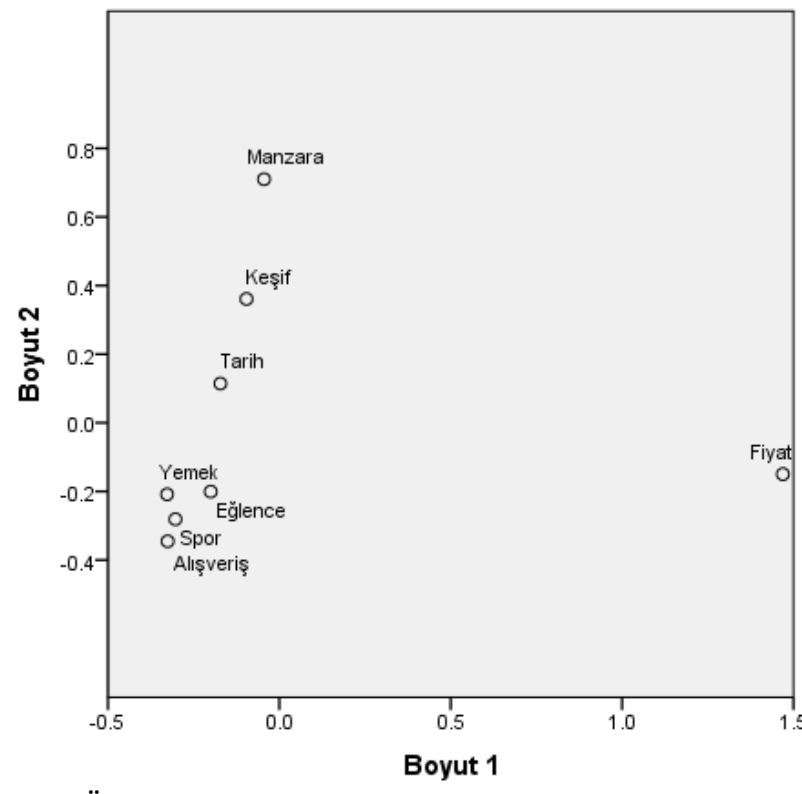

Şekil 6: Öne çıkarılan özelliklerin iki boyutlu uzayda gösterimi

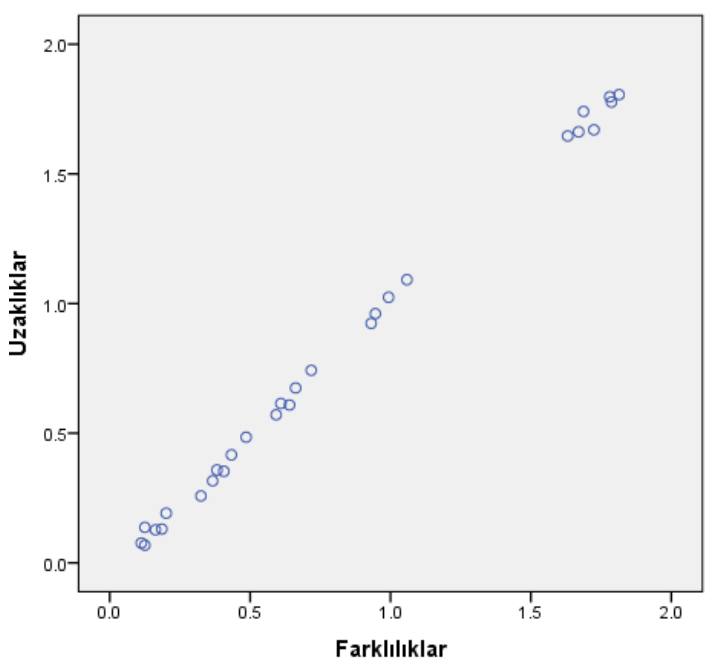

Şekil 7: Öne çıkarılan özelliklerin uzaklıklar ile farklılıklar arasındaki ilişkinin diyagramı

Şekil 6' ya bakıldığında THY tarafından bir seyahat tavsiyesi nedeni olarak sunulan fiyat unsurunun diğerlerinden keskin bir biçimde ayrıştığı görülmektedir. Bu durumda THY takipçilerinin fiyat ile ilgili içeriklere daha fazla eğilim gösterdiği düşünülebilmektedir. Ayrıca manzara, keşif ve tarih unsurlarının da birbirlerinden ve diğerlerinden ayrıştığı görülmekle birlikte yemek, spor, eğlence ve alışveriş unsurlarının bir kümede toplandığı gözlenmektedir. Şekil 5' te yer alan ülkelerle birlikte değerlendirildiğinde İspanya, Fransa, İtalya, Portekiz, Malta ve Yunanistan' ın haritada fiyat unsuruna yaklaşığı, Türkiye' nin manzara unsuruyla öne çıktığı ve Küba, Seyşeller, Lüksemburg ve ABD ile birlikte keşif ve tarihe yaklaştığı görülmektedir. Kullanıcıların yemek, eğlence, spor ve alışveriş unsurlarını gözeterek diğer ülkelere eğilim gösterdiği de sonuçlardan bir başka yorum olarak karşımıza çıkmaktadır.

\section{SONUÇ}

Dijital iletişimin vazgeçilmez bir unsuru haline gelen sosyal medya ve bu medyayı kullanan kişilerin çevrimiçi davranışı, işletmeler için de yeni pazarlama stratejilerinin kaynağı haline gelmektedir. Sosyal medyanın gittikçe popülerleşen uygulamaları arasında yer alan Twitter ise milyonlarca aktif kullanıcısı ve sürekli akan veri trafiği ile işletmelerin ürün ve hizmetleri hakkında anında geri dönüt alabilecekleri bir platforma dönüşmektedir. Dolayısıyla işletmelerin resmi Twitter adreslerinden takipçilerine sundukları görsel ve yazılı içerikler hakkında tüketici ve müşterilerin tepkisi oldukça önem arz etmektedir.

Analiz sonuçlarına bakıldığında Türkiye' nin diğer destinasyonlardan keskin bir biçimde ayrıştığı görülmektedir. Tavsiye nedenlerinin iki boyutlu uzaydaki gösterimiyle bu sonuçlar ele alındığında fiyat unsurusunun ön plana çıktığı görülmektedir. Bu da takipçilerin fiyat öne çıkarılarak yapılan destinasyon paylaşımlarına daha çok eğilim gösterdiği sonucunu doğurmaktadır. Ayrıca destinasyonlara tavsiye nedeni olarak verilen manzara, tarih ve keşif unsurlarının bir küme içinde; yemek, eğlence, spor ve alışveriş unsurlarının ise başka bir küme içerisinde tüketiciler tarafından paylaşım verileri gözetilerek benzer eğilime maruz kaldıkları ortaya çıkmaktadır. Bu kümelenmeler ülke kümelenmeleriyle birleştirildiğinde Türkiye' nin daha çok manzara; Amerika kıtasındaki ve Avrupa' da yer alan birtakım ülkelerin manzara, tarih, keşif, yemek, eğlence, spor ve alışveriş; diğer Avrupa ülkelerinin ise fiyat unsurlarıyla öne çıktı̆̆ görülmektedir. Bu doğrultuda fiyat ve manzara unsurlarıyla öne çıkan destinasyonlara yönelik tanıtım ve yatırımların sosyal medyada daha çok rağbet göreceği ve bu tavsiye nedenlerine yoğunlaşılması gerektiği söylenebilmektedir.

Devam eden çalışmalarda benzer sosyal medya verilerinin farklı istatistiksel tekniklerle analiz edilmesi ve sonuçların oraya konmasının literature katkıda bulunacağı düşünülmektedir. 


\section{KAYNAKÇA}

Asur, S ve Huberman, B. A. (2010, August). Predicting The Future With Social Media. In Web Intelligence And Intelligent Agent Technology (WI-IAT), 2010 IEEE/WIC/ACM International Conference On (Vol. 1, Ss. 492-499). IEEE.

Berthon P. R., Pitt L ve Campbell C. (2008). When Customers Create The Ad. California Management Review. 50(4), 6-30.

Borg, I ve Groenen, P. J. (2005). Modern Multidimensional Scaling: Theory And Asslications. Springer Science \& Business Media.

Boyd, D., Golder, S ve Lotan, G. (2010, January). Tweet, Tweet, Retweet: Conversational Aspects Of Retweeting On Twitter. In System Sciences (HICSS), 2010 43rd Hawaii International Conference On (Ss. 1-10). IEEE.

Busing, F. M. T. A., Commandeur, J. J., Heiser, W. J., Bandilla, W ve Faulbaum, F. (1997). PROXSCAL: A Multidimensional Scaling Program For Individual Differences Scaling With Constraints. Softstat, 97, 67-74.

Bülbül, S ve Köse, A. (2010). Türkiye'de Bölgelerarası İç Göç Hareketlerinin Çok Boyutlu Ölçekleme Yöntemi İle İncelenmesi. İstanbul Üniversitesi İşletme Fakültesi Dergisi, 39(1), 75-94.

Heinonen, K. (2011). Consumer Activity İ Social Media: Managerial Assroaches To Consumers' Social Media Behavior. Journal Of Consumer Behaviour, 10(6), 356-364.

Kalaycı, Ş. (2005). SPSS Uygulamalı Çok Değişkenli İstatistiksel Teknikleri. Asil Yayın Dağıtım Ltd: İstanbul, Ss.379-396.

Hair, J.F. Anderson, R.E., Tatham, R. L ve W. C. (1998). Black, Multivariate Data Analysis. Fifth Edition, Prentice-Hall Inc: USA. Ss.536-539.

Kaplan, A. M ve Haenlein, M. (2010). Users Of The World, Unite! The Challenges And Ossortunities Of Social Media. Business Horizons, 53(1), 59-68.

Köksal, Y ve ÖZDEMiR, ş. (2013). Bir İletişim Aracı Olarak Sosyal Medya'nın Tutundurma Karması İçerisindeki Yeri Üzerine Bir İnceleme. Süleyman Demirel Üniversitesi İktisadi Ve İdari Bilimler Fakültesi Dergisi, 18(1).

Kruskal, J. B. (1964). Multidimensional Scaling By Optimizing Goodness Of Fit To A Nonmetric Hypothesis. Psychometrika, 29(1), 1-27.

Mangold, W. G ve Faulds, D. J. (2009). Social Media: The New Hybrid Element Of The Promotion Mix. Business Horizons, 52(4), $357-365$.

Oğuzlar, A. (2005b), "Çok Boyutlu Ölçekleme Analizi Yardımıyla Avrupa Birliği Üyeliğini Etkileyen Faktörlerin Konumlandırılması”, Uludağ Üniversitesi İktisadi Ve İdari Bilimler Fakültesi Dergisi, 24(1), S. 33-43.

Tüzüntürk, S. (2009). Çok Boyutlu Ölçekleme Analizi: Suç İstatistikleri Üzerine Bir Uygulama. Uludağ Üniversitesi İktisadi Ve İdari Bilimler Fakültesi Dergisi, 28(2), 71-91.

VURAL, Z. B. A ve Batb, M. (2010). Yeni Bir İletişim Ortamı Olarak Sosyal Medya: Ege Üniversitesi İletişim Fakültesine Yönelik Bir Araştırma Socıal Medıa As A New Communıcatıon Envıronment: A Research On Ege Unıversıty Faculty Of Communıcatıon. Journal Of Yasar Uni

Whiting, A. ve Williams, D. (2013). Why people use social media: a uses and gratifications approach. Qualitative Market Research: An International Journal, 16(4), 362-369. 